\title{
FROM EMISSION TO IMMISSION: THE WAY TO PERTINENT EVALUATION OF TRANSPORT-RELATED HEALTH AND ENVIRONMENTAL IMPACTS
}

\author{
J-P. MORIN, F. GOURIOU, D. PRETERRE \& F. DIONNET \\ CERTAM (Centre de Recherches Technologiques en Aérothermique et Moteurs), \\ Saint Etienne du Rouvray, France.
}

\begin{abstract}
This contribution focusses on emission/immission contribution assessment of road transport to global pollution source apportionment. The recent evolution in this domain show the impressive reduction of tailpipe emissions when brake and tyre wear PM emissions become the major source of recent powertrains. Inside vehicle immissions have been assessed using a vehicle inserted in the traffic as a 'mobile laboratory'. These immissions may represent the major part of the daily personal space-time exposure budget to air pollution. As an example, each hour spent in a car cabin may represent to a 1 hour exposure above the WHO recommendation limits for both PM and NO2. Time course evolution of car cabin immissions shows an important reduction of PM exposure thanks to the Euro5 regulation which made mandatory the use of particulate filters on light duty diesel-powered vehicles. In the meantime, recent toxicological studies demonstrate the impressive reduction of genotoxity, carcinogenicity, and pro-inflammatory potentials of post Euro5 diesel-vehicle emissions. As a conclusion, the impressive reduction of post Euro5 diesel-vehicle tailpipe emissions leads to a reduction of traffic-related pollutant immissions which will further improve with the expected growing of Euro6 complying vehicles in the forthcoming years.

Keywords: atmospheric pollution, emissions, health effects, immissions, nitrogen oxides, particulate matter, personal exposure, space-time exposure budget traffic.
\end{abstract}

\section{INTRODUCTION}

Road transport tailpipe emissions and more specifically diesel engine-powered vehicle emissions are most frequently claimed as being the major source of city air quality degradation. Diesel engine-powered vehicles. In this respect, WHO classified diesel engine-emitted particulate as class 1 carcinogen to humans in 2012 [1], and atmospheric pollution as class 1 carcinogen to humans in 2013 [2]. Tailpipe particulate matter emissions especially from diesel engines have been tremendously reduced due to the onset of Euro5 regulation on engine emissions that rendered mandatory the use of closed particulate filters on the exhaust lines for diesel engine-powered vehicles produced since year 2011. This very efficient (over 95\%) reduction of diesel soot emissions led to take into account the friction particulate emissions from brake wear and tire wear as becoming a new concern from vehicle powertrain emissions. We will consider three sections in this contribution: the first section will be dedicated to the assessment of particulate matter source apportionment during seasonal particulate matter pollution episodes, the second section will be dedicated to the assessment of daily personal exposure budget with a specific approach of car cabin exposure compared to other transportation choices. Finally, the third section will be dedicated to recent time course evolution of car 
cabin immission and the extensive reduction of diesel-engine emission genotoxicity and inflammatory potentials according to emission after-treatment strategies.

\section{ATMOSPHERIC POLLUTANT SOURCE APPORTIONMENT}

An overview of the French pollutant emission inventory published by CITEPA [3] shows a constant reduction of pollutant emissions since at least year 1990. Figures 1-3 summarize this observation for particulate matter, NOx, and non-methane VOC.

It is of interest that for these pollutant, reduction of road transport contribution by $90 \%$ for NMVOC, $60 \%$ for NOx, 70\% for PM1, is one of the most important triggers responsible for the improvement of global emission reduction thanks to the advanced technologies in the field of engine exhaust after-treatment namely there way catalysis on spark-ignited engines and oxidation catalysis and particulate filters on diesel engines. As shown in Figs 4 and 5, these improvements remain highly significant when expressed per inhabitant and or per ton equivalent petroleum thus confirming the improvement achieved in the field of anthropic source depollution strategies.

Since year 2007, particulate matter monitoring by air quality networks is performed using the TEOM/FDMS technology including the semi-volatile fraction of particulate matter which was not formerly included when using the TEOM technology. This change in particulate assessment technology had a very significant impact on particulate matter levels especially during spring particulate matter pollution episodes where a high semi-volatile fraction made essentially of ammonium nitrate and ammonium sulfate is observed as shown in Fig. 6 and described in Rouil et al. [4].

In year 2011, particulate matter threshold have been significantly reduced from 120 to 80 and from 80 to $50 \mu \mathrm{g} / \mathrm{m}^{3}$ for population alert and information, respectively. Both actions have been responsible for an artificial increase of the number of alerts while in the meantime

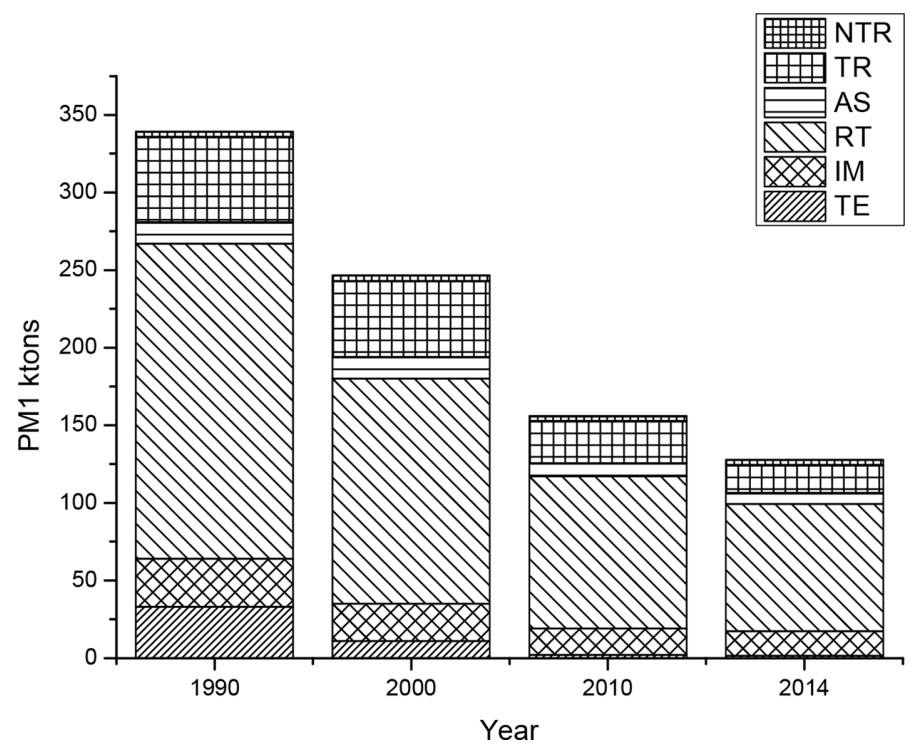

Figure 1: PM1 emission source apportionnement for France. kton/year. Data calculated from [3]. NTR non road transport, TR road transport, AS Agriculture and forest, RT residential and tertiary, IM Indusctry Manufacture, TE Energy transformation. 


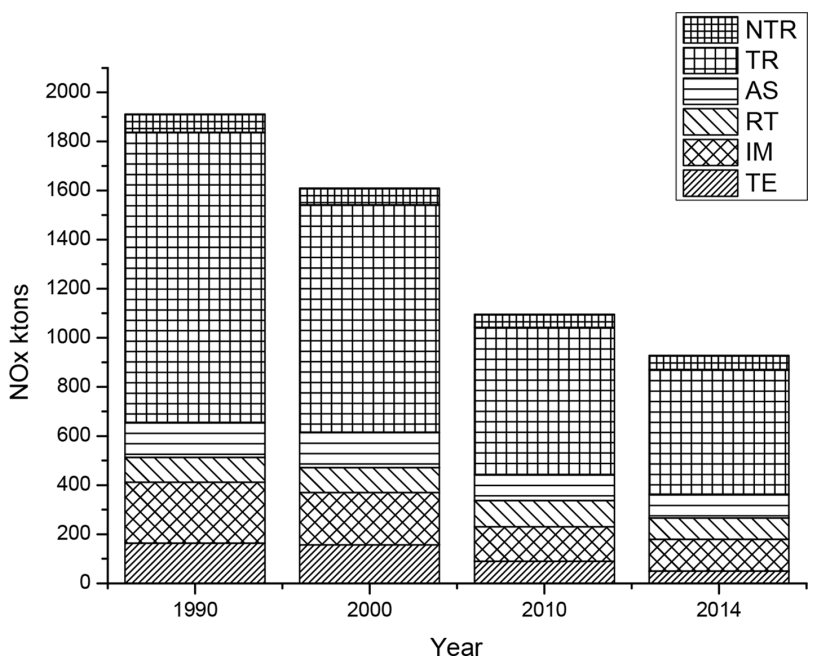

Figure 2: NOx emission source apportionnement for France. kton/year. Data calculated from [3]. NTR non road transport, TR road transport, AS Agriculture and forest, RT residential and tertiary, IM Indusctry Manufacture, TE Energy transformation.

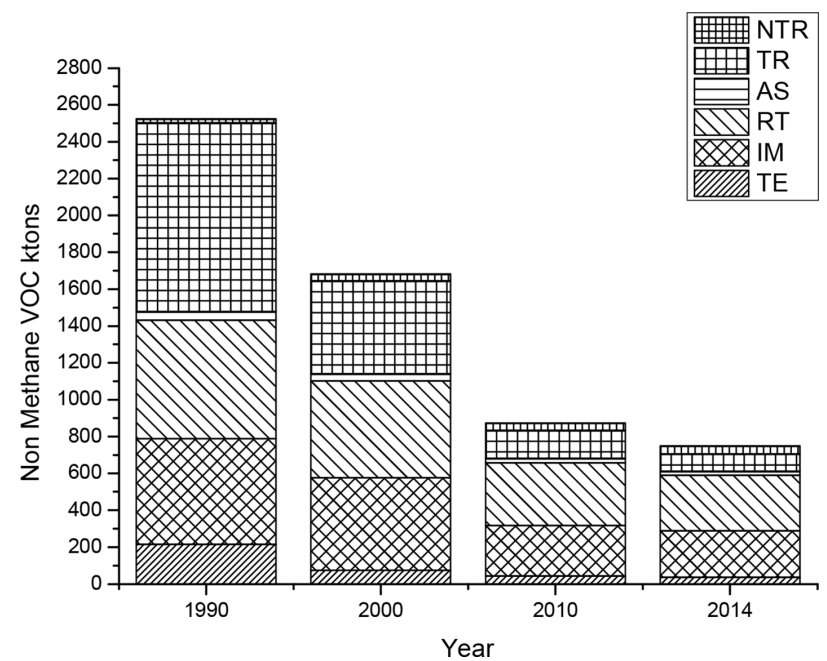

Figure 3: Non methane VOC emission source apportionnement for France. kton/year. Data calculated from [3]. NTR non road transport, TR road transport, AS Agriculture and forest, RT residential and tertiary, IM Indusctry Manufacture, TE Energy transformation.

atmospheric particulate matter concentrations significantly decreased as reported by AirParif [5] and the French minister of environment [6] although some yearly very typical PM episodes are observed in March. Interestingly enough, these particulate matter pollution episodes observed during early spring periods since the introduction of TEOM/FDMS metrology would not have been considered as such when using TEOM metrology only since solid particles did not exceed the $50 \mu \mathrm{g} / \mathrm{m}^{3}$ threshold (Fig. 6). During these episodes, a very peculiar 


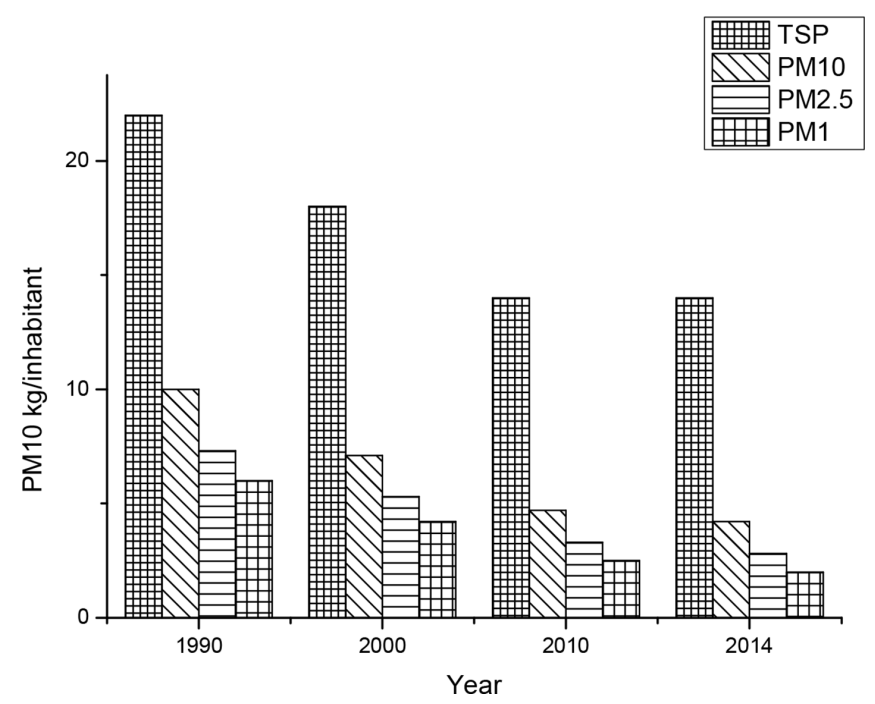

Figure 4: Evolution of French particulate matter per French citizen. TSP total suspended particulate matter, PM10 PM below $10 \mu \mathrm{m}$, PM2.5 PM below $2.5 \mu \mathrm{m}$, PM1 PM below $1 \mu \mathrm{m}$.

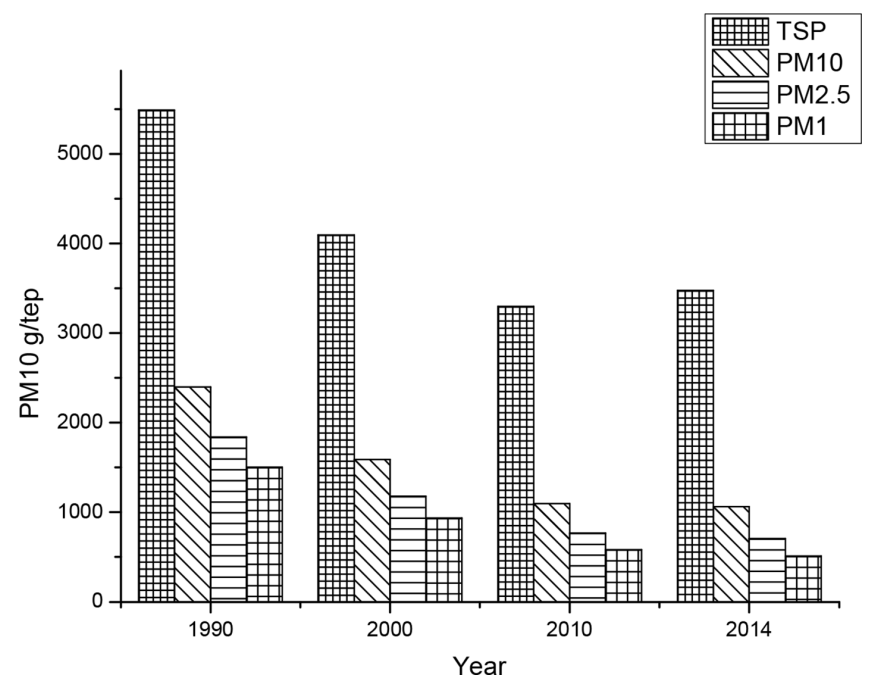

Figure 5: Evolution of French particulate matter per ton equivalent petroleum. TSP total suspended particulate matter, PM10 PM below $10 \mu \mathrm{m}$, PM2.5 PM below $2.5 \mu \mathrm{m}$, PM1 PM below $1 \mu \mathrm{m}$.

elevation of PM10 volatile/solid PM ratio which is not occurring during other periods of the year. These episodes are not at all followed by any significant health impacts such as increased hospital admissions, asthma or bronchitis exacerbation Host et al. [7]. Particulate matter chemical composition as assessed by the French national program CARA appears to be very 
specific during these episodes, with a very high contribution of nitrates, ammonium and sulfate which may exceed 50\% of PM10 and account for the vast majority of volatile PM10 fraction [8].

Concerning epidemiology studies and elaboration of European recommendations for population information and alerts, it is all the most important to take into account that most of the European relative risk data still in use today were elaborated in the frame of the APHEA [9, 10], APHEIS [11] and APHEKOM [12] projects which took place before the implementation of air quality monitoring networks with the TEOM-FDMS. Data for PM measurements were thus not including the volatile fraction of PM. In view of these considerations, one may question the potential interest of the inclusion of the volatile fraction of PM for the onset of PM information and alert procedures at least during the spring PM10 episodes which represent ca. $90 \%$ of the yearly observed PM10 episodes in the north of France.

\section{DAILY PERSONAL SPACE-TIME EXPOSURE BUDGET EVALUATIONS}

Usual air quality/health impact epidemiologic studies are related to outdoor urban air pollutant concentrations provided by air quality monitoring networks. However, it is well-known that major significant variations of personal exposure levels occur with different environments to be visited, as well as the significant increase of personal exposure levels associated with some activities along a day. This has led epidemiology scientists to elaborate spacetime-budget studies. In a first approach, they have considered the time spent at home as an important data to estimate exposure to indoor pollutants. The average daily time spent in the home was 16 hours and 10 minutes. This represents $67 \%$ of the daily time (71\% for women and $63 \%$ for men). Data can be collected from French observatory of indoor air quality 2005.

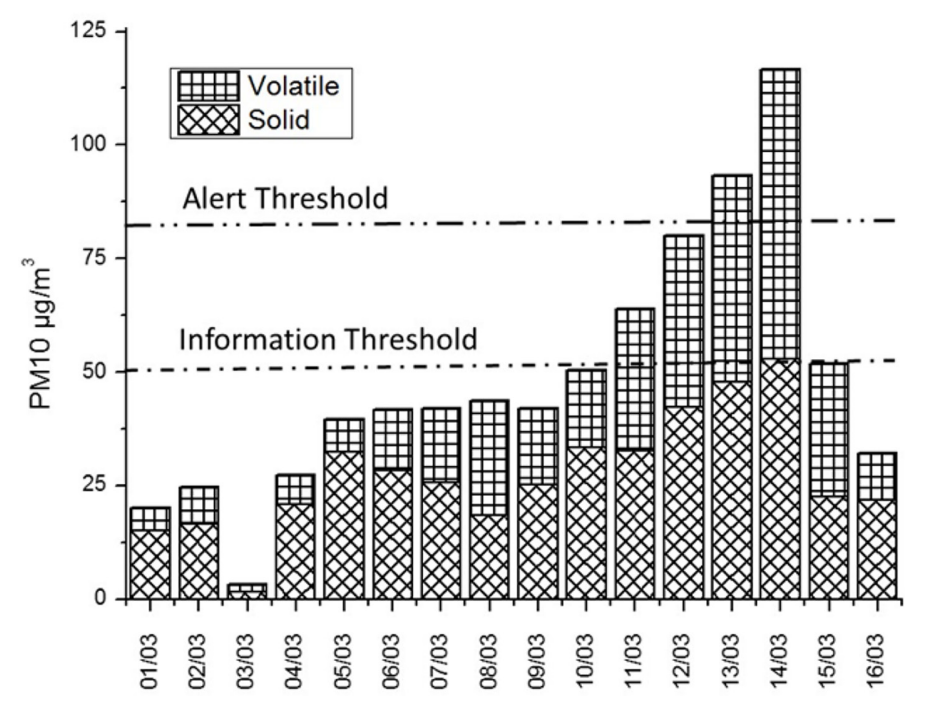

Figure 6: Typical example of volatile and solid PM10 fractions during early spring PM10 episodes in the north of France. PM episode of March 2014 in Rouen city, calculation made from AirNormand monitoring network data. Solid: measurement with TEOM, Volatile: TEOM-FDMS minus TEOM measurement, total stack: TEOM-FDMS measurement. Values are 24 hour mean values. 
(http://www.invs.sante.fr/publications/2010/exposition_co_logement/rapport_expo_logement.pdf)

In this study, we show that cabin air quality is a specific environment which may contribute very significantly to the daily space-time-budget of exposure to pollutant. In large cities, for daily commuting or for worker categories as taxi or lorry drivers, time spent in the traffic may

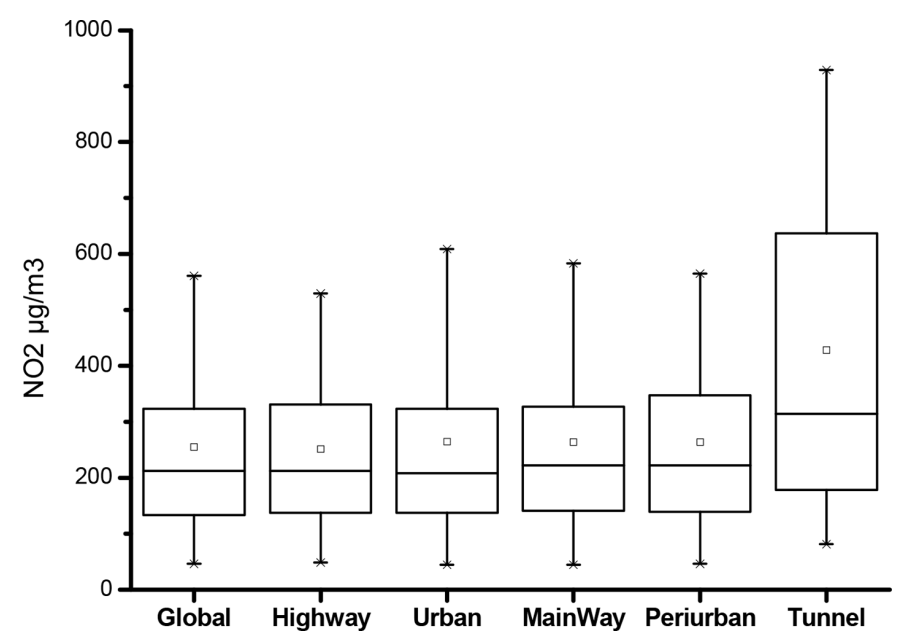

Figure 7: In car cabin, $\mathrm{NO}_{2}$ concentrations according to the driving situation. Exposilla study [14]. Data are presented as box plots (centiles 5, 25, 50, 75, and 95) of recorded data during $4500 \mathrm{~km}$ for Global. Measurement were every each second with two analysers (AC32M and T32M Environnement SA France)) to cover the high dynamic range of concentrations encountered.

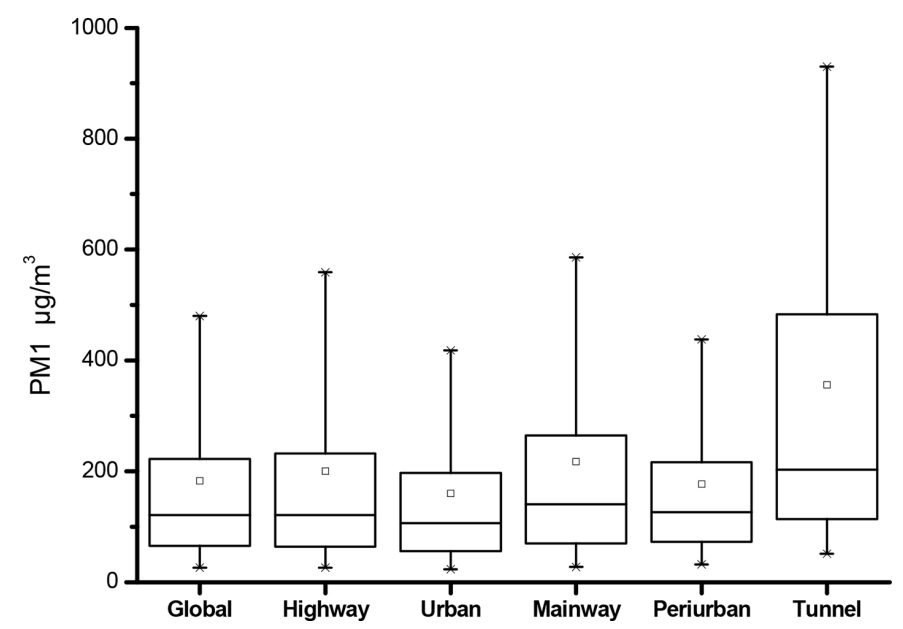

Figure 8: In car cabin PM1 concentrations according to the driving situation. Exposilla study [14]. Data are presented as box plots (centiles 5, 25, 50, 75 and 95) of recorded data during $4500 \mathrm{~km}$ for Global. Measurements were every each second using the conversion of ELPI (Dekati Finland) total current values. 
last from 1 to 10 hours. Since about 10 years from now, we started to study the evolution of pollutant concentrations namely $\mathrm{NO}_{2}, \mathrm{NOx}$ and particulate matter in the cabin of cars inserted in the traffic $[13,14]$. We clearly demonstrated that extremely high $\mathrm{PM}$ and $\mathrm{NO}_{2}$ concentrations were encountered in this confined area due to the situation of the vehicle in the exhaust plume of the preceding vehicle. As shown in Figs 7 and 8, few differences were observed between traffic situations such as urban, peri-urban highways. As a short summary of measurements every each second during more than $4500 \mathrm{~km}$ in 2007-2008, each hour spent in a vehicle inserted in the traffic may represent an exceed of WHO recommendation limits for exposure to both $\mathrm{NO}_{2}$ and particulate matter. These concentrations are 3 to 5 times as big on average as those measured by air quality network on road side

\section{TIME COURSE EVOLUTION OF CAR CABIN IMMISSIONS}

These observations clearly show that car cabin is one of the most polluted environments for general population exposure. This environment should thus definitely be taken into account for personal space-time budget evaluations since we could estimate that 1 hour spent in a vehicle might represent as much as $50 \%$ of total personal daily exposure to either $\mathrm{NO}_{2}$ or particulate matter. Major time course evolution of car cabin $\mathrm{NO}_{2}, \mathrm{NOx}$, and $\mathrm{PM}$ concentrations has been observed over the last decade: Figs 9-11 show that using similar measurement protocols, in car cabin NO2, NOx and PM concentrations significantly increased from year 2007 to year 2010. This increase was followed by a significant reduction from year 2010 to year 2015, with a more extensive decrease for PM1 than for $\mathrm{NO}_{2}$ or NOx. These variations can be explained by the introduction of particulate filters in year 2011 with the Euro5 regulation on diesel personal cars and light duty vehicles. This introduction of very efficient particulate filters allowed the use of increased exhaust gas recirculation as a strategy for NOx reduction to comply with the Euro5 regulation which was also more stringent than Euro4 regulation for NOx emission.

Figure 12 shows that The PM/NOx ratio continuously decreased from 2007 to 2015 as a result of technological depollution strategies rendered necessary to comply with the Euro

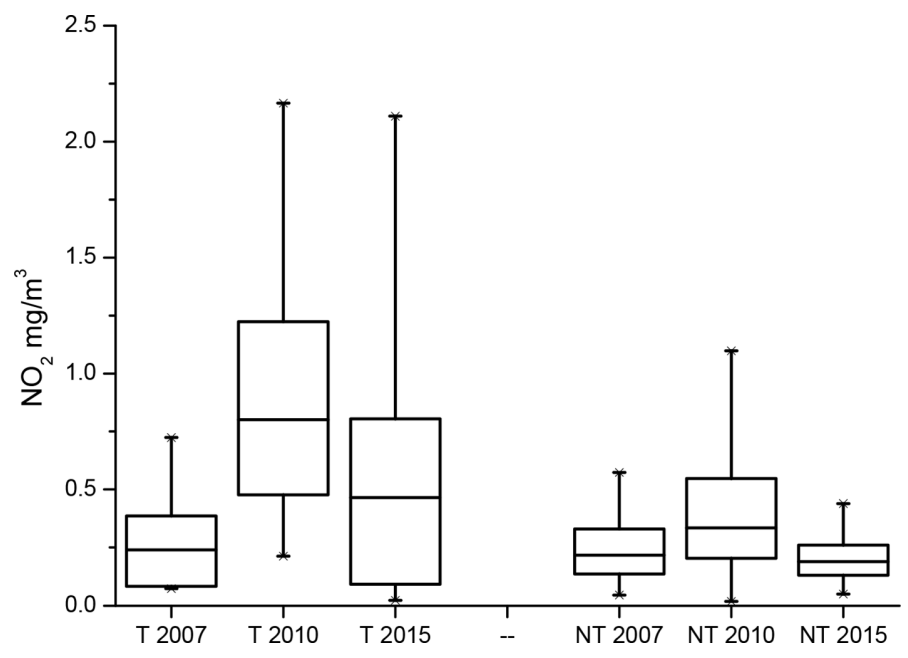

Figure 9: Time course evolution of car cabin $\mathrm{NO}_{2}$ concentrations over the last decade. $\mathrm{T}$ inside tunnel concentrations, NT outdoor concentrations. Data are presented as box plots (centiles 5, 25, 50, 75, and 95). 


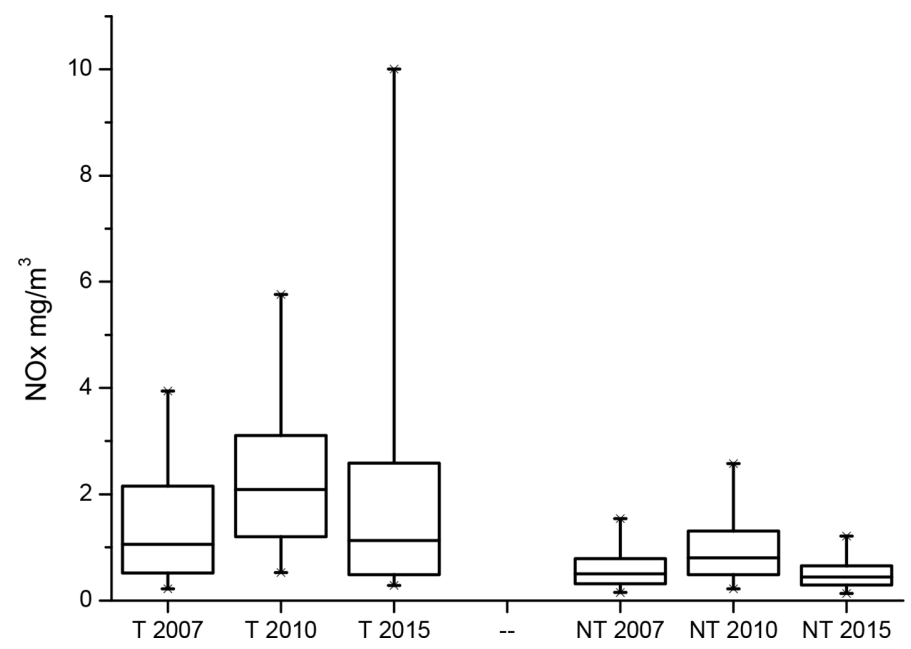

Figure 10: Time course evolution of car cabin NOx concentrations over the last decade. T inside tunnel concentrations, NT outdoor concentrations. Data are presented as box plots (centiles 5, 25, 50, 75, and 95).

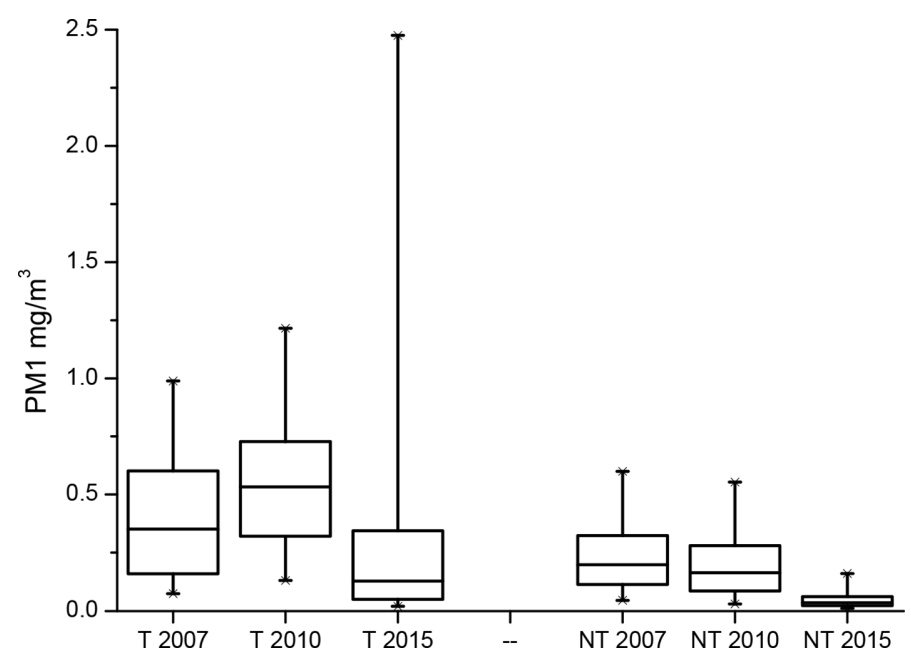

Figure 11: Time course evolution of car cabin PM1 concentrations over the last decade. $\mathrm{T}$ inside tunnel concentrations, NT outdoor concentrations. Data are presented as box plots (centiles 5, 25, 50, 75, and 95).

regulation evolution. It is expected to see a further reduction of both $\mathrm{NO}_{2}$ and $\mathrm{NOx}$ emissions in the forthcoming years as a result of Euro 6 regulation complying vehicles coming to the market since October 2015.

\section{CONCLUSIONS}

We could demonstrate that the specific environment inside the vehicles inserted in the traffic is a highly polluted area which may contribute to $50 \%$ of the daily space-time exposure 


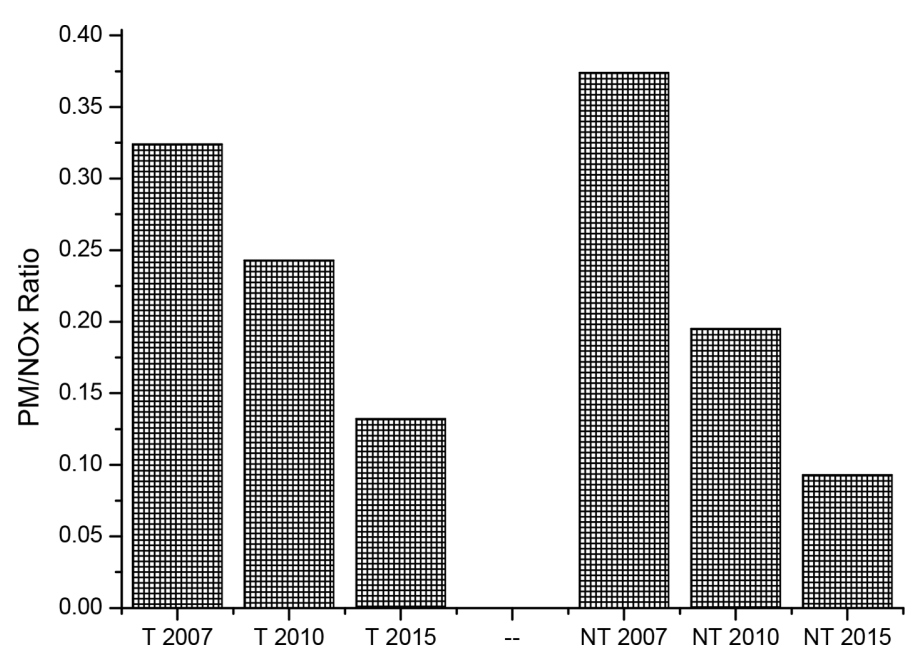

Figure 12: Time course evolution of car cabin PM/NOx concentration ratios over the last decade. T inside tunnel concentrations, NT outdoor concentrations.

budget. This environment pollutant immission is directly related to the quality of the vehicle exhausts in the close vicinity more than to the general outdoor pollution levels. Interestingly enough, the improvement of engine emission after-treatment strategies have a direct impact on the improvement of car cabin air quality and of the air quality in the proximity of the traffic as shown by our measurement and measurements from air quality monitoring networks, respectively, during the last decade. These observations on real life immission due to traffic emissions are very important to calibrate inhalation toxicological studies with pertinent aerosol dosimetry to the biological targets as conducted in our laboratory with either in vitro or in vivo models exposed for several hours to continuous flows of aerosols with controlled physicochemistry to assess acute biological responses. [15-17]. These observations may also be very important to help decision makers for the choice of the most suitable solutions to fight against specific pollutant emission sources owing their actual contribution to pollution apportionment and specific health impacts facing the variation of seasonal pollution episodes.

\section{ACKNOWLEDGMENTS}

Authors would like to thank ANSES and ADEME for their financial support, AIRTURIF and Air Normand for their kind cooperation.

\section{REFERENCES}

[1] Benbrahim-Tallaa, L., Baan, R.A., Grosse, Y., Lauby-Secretan, B., El Ghissassi, F., Bouvard, V., Guha, N., Loomis, D. \& Straif, K., Carcinogenicity of diesel-engine and gasoline-engine exhausts and some nitroarenes. The Lancet Oncology, 13(7), pp. 663664, 2012.

http://dx.doi.org/10.1016/S1470-2045(12)70280-2

[2] Loomis, D., Grosse, Y., Lauby-Secretan, B., El Ghissassi, F., Bouvard, V., Benbrahim-Tallaa, L., Guha, N., Baan, R., Mattock, H. \& Straif, K., The carcinogenicity of outdoor air pollution. The Lancet Oncology, 14(13), pp. 1262-1263, 2013. http://dx.doi.org/10.1016/S1470-2045(13)70487-X 
[3] Serveau, L., Taïeb, N., Chang, J.P., Vincent, J., and others, Inventaire des émissions de polluants atmosphériques et de gaz à effet de serre en France - Séries sectorielles et analyses étendues. CITEPA, April 2015.

[4] Rouïl, L., Bessagnet, B., Favez, O., Leoz- Garziandia, E. \& Meleux, F., Particulate air pollution episodes in France: lessons learnt from recent episodes. Pollution atmosphérique. numéro special, pp. 101-114, March 2015.

[5] AirParif, Surveillance et information sur la qualité de l'air à Paris en 2014, Avril 2015, available at www.airparif.asso.fr

[6] Bottin, et al. Bilan de la qualité de l'air en France en 2014 et principales tendances sur la période 200-2014, available at http://www.developpement-durable.gouv.fr/Publicationdu-bilan-2014-de-la.html

[7] Host, S., Karusisi, N., Fiori, M., Fouillet, A. \& Caserio-Schönemann, C., Analyse de l'impact sanitaire d'un épisode de pollution : retour d'expérience sur la surveillance syndromique lors de l'épisode de mars 2014. Pollution atmosphérique. Numéro special, pp. 179-184, 2015.

[8] Fritz, A., Duga, F., and others. Bilan de l'épisode de pollution de mars 2014 et évaluation de la mise en place de la circulation alternée le 17 mars 2014 en Ile-de-France. Pollution atmosphérique. Numéro special, pp. 101-114, 2015.

[9] Katsouyanni, K., Schwartz, J., Spix, C., Touloumi, G., Zmirou, D., Zanobetti, A., Wojtyniak, B., Vonk, J.M., Tobias, A., Ponka, A., Medina, S., Bacharova, L. \& Anderson, H.R., Short term effects of air pollution on health: a European approach using epidemiologic time series data: the APHEA protocol. Journal of Epidemiology \& Community Health, 50(Suppl 1), S12-S18, 1996.

http://dx.doi.org/10.1136/jech.50.Suppl_1.S12

[10] Katsouyanni, K., Zmirou, D., Spix, C., Sunyer, J., Schouten, J.P., Ponka, A., Anderson, H.R., Le Moullec, Y., Wojtyniak, B. \& Vigotti, M.A., Short-term effects of air pollution on health: a European approach using epidemiological time-series data. The APHEA project: background, objectives, design. European Respiratory Journal, 8(6), pp. 1030 1038, 1995.

[11] Medina, S., Le Tertre, A. \& Saklad, M; on behalf of the Apheis Collaborative Network, The apheis project: air pollution and health-a European information system. Air Quality Atmosphere and Health, 2(4), pp. 185-198, 2009. http://dx.doi.org/10.1007/s11869-009-0050-2

[12] Perez, L., Declercq, C., Iñiguez, C., Aguilera, I., Badaloni, C., Ballester, F., Bouland, C., Chanel, O., Cirarda, F.B., Forastiere, F., Forsberg, B., Haluza, D., Hedlund, B., Cambra, K., Lacasaña, M., Moshammer, H., Otorepec, P., Rodríguez-Barranco, M., Medina, S. \& Künzli, N., Chronic burden of near-roadway traffic pollution in 10 European cities (APHEKOM network). European Respiratory Journal, 42(3), pp. 594-605, 2013. http://dx.doi.org/10.1183/09031936.00031112

[13] Gouriou, F., Morin, J.P. \& Weill, F., On-road measurements of particle number concentrations and size distributions in urban and tunnel environments. Atmospheric Environment, 38(18), pp. 2831-2840, 2004.

http://dx.doi.org/10.1016/j.atmosenv.2004.02.039

[14] Morin, J.P., Gouriou, F., Preterre, D., Bobbia, M. \& Delmas, V., Evaluation de l'exposition aux polluants atmosphériques des conducteurs de véhicules automobiles par la mise en œuvre de mesures dynamiques dans l'habitacle du véhicule. Archives des Maladies Professionnelles et de l'Environnement, 70(2), pp. 184-192, 2009. http://dx.doi.org/10.1016/j.admp.2008.10.024 
[15] Anselme, F., Loriot, S., Henry, J.P., Dionnet, F., Napoleoni, J.G., Thuillez, C. \& Morin, J.P., Inhalation of diluted diesel engine emission impacts heart rate variability and arrhythmia occurrence in a rat model of chronic ischemic heart failure. Archives of Toxicology, 81(4), pp. 299-307, 2007.

http://dx.doi.org/10.1007/s00204-006-0147-4

[16] Morin, J.P., Hasson, V., Fall, M., Eleni, P., Preterre, D., Gouriou, F., Keravec, V., Konstandopoulos, A. \& Dionnet, F., Prevalidation of in vitro continuous flow exposure systems as alternatives to in vivo inhalation safety evaluation experimentations: outcome from MAAPHRI-PCRD5 research program. Experimental and Toxicological Pathology, 60(2-3), pp. 195-205, 2008.

http://dx.doi.org/10.1016/j.etp.2008.01.007

[17] André, V., Barraud, C., Capron, D., Preterre, D., Keravec, V., Vendevillle, C., Cazier, F., Pottier, D., Morin, J.P. \& Sichel, F., Comparative mutagenicity and genotoxicity of particles and aerosols emitted by the combustion of standard vs. rapeseed methyl ester supplemented bio-diesel fuels: impact of after treatment devices: oxidation catalyst and particulate filter. Mutation Research/Genetic Toxicology and Environmental Mutagenesis, 777, pp. 33-42, 2015.

http://dx.doi.org/10.1016/j.mrgentox.2014.11.007 